\title{
Participation of Rural Women in Decision Making Process of Dairy Farming in Surguja District of Chhattisgarh, India
}

\author{
Ankur Gupta ${ }^{1 *}$, Anindita Saha ${ }^{1}$, Ravi Kumar Gupta ${ }^{1}$ and Digvijay Singh Dhakre ${ }^{2}$ \\ ${ }^{1}$ Department of Agricultural Extension, ${ }^{2}$ Department of Agricultural Statistics, \\ Palli Siksha Bhavana (Institute of Agriculture), \\ Visva-Bharati University, Sriniketan (W.B.), India \\ *Corresponding author
}

\begin{abstract}
A B S T R A C T
The women folk are considered the backbone of the nation and better half of the men in almost all spheres of community development. Rural women constitute about $50 \%$ of the total rural population. The present study was conducted in Surguja district of Chhattisgarh to know the Participation of rural women in the decision-making process of dairy farming. Data were collected from 120 rural women using a structured interview schedule. 30 women farmers were chosen from each selected village thus constituting a sample size of 120 by simple random method. All of the respondents $(100 \%)$ had medium participation (46.4to88.2\%) as none of the respondents belonged to low or high participation groups in the decision-making process in Dairy farming. Correlation Coefficient between the selected characteristics of the respondents with participation in Dairy farming was also worked out and the value of the correlation coefficient was found out. It is clear from the data that out of all selected 10 variables only 1 variable Annual income was found positive and significantly correlated with Extent of participation of rural women in the Decision-making process in Dairy farming practices. The remaining variables did not indicate any significant relationship with the extent of participation of rural women in the decision-making process in Dairy farming. Path analysis shows that annual income had the highest total effect on the participation of rural women in the decision making process of dairy farming where family type and Social participation has been the second and third passion of total effect on Participation of rural women in the decision-making process of dairy farming respectively. Dairy farming in the study area holds a very good future because certain dairy farming related operations and taking decisions farm women better than male farmers.
\end{abstract}

\section{Keywords}

Dairy farming, Animal husbandry, Social participation, Decision making

\section{Article Info}

Accepted:

21 May 2020

Available Online:

10 June 2020

\section{Introduction}

The rural women play a significant role in agriculture and other agro-based activities. The daily work schedule of rural women is very demanding and arduous. It is very estimated that during peak periods, women work for 8-9 hours in agriculture and 4 hours in household activities. The women folk are considered the backbone of the nation and better half of the men in almost all spheres of community development. Rural women constitute about $50 \%$ of the total rural population.

They play a vital role in all spheres of economic life and contribute richly towards national income. Dairy enterprise has been 
regarded as an important instrument of economic and social change and supplement to the income and employment to rural women. There are certain agricultural operations in which female agricultural workers are considered better than male workers. Dairying, being an occupation, women from these families is also partners in animal husbandry activities' management as managers, decision-makers, and skilled workers. India is predominantly an agrarian society where animal husbandry forms the backbone of the national economy. India is the largest producer of milk in the World. From 66.2 million tonnes in 1995-96, milk production has increased steadily to 155.5 million tones in 2015-16. The average annual rate of growth of milk production is 4 percent from 2000-01 to 2010-11. In 2010-11, the estimated growth is 4.66 percent over the previous year. Per capita availability of milk has gone up from 195 gm per day in 1995-96 to $276 \mathrm{~g}$ per day in $2010-11$.

However, it is well above the World's average per capita availability. Global average per capita availability was $286 \mathrm{~g}$ per day in 2011-12 compared to $290 \mathrm{~g}$ per day for India. India's livestock sector is one of the largest in the World. In the World, India ranks first in cattle and buffalo population, second in goat, third in sheep, and seventh in poultry. India has 56.7 percent of the World's buffaloes, 12.5 percent cattle, 20.4 percent small ruminants, 2.4 percent camel, 1.4 percent equine, 1.5 percent pigs, and 3.1 percent poultry of the World. In 2010-11, livestock generated outputs worth Rs. 2075 billion (at 2004-05 prices) which comprised 4 percent of the GDP and 27 percent of the agricultural GDP. The total output worth was higher than the value of food grains. Milk production increased from around 20 million tones in the 1960 s to 155 million tonnes in 2015-16. It grew at an annual rate of $4.4 \%$ during the 1990 s and $3.8 \%$ during the 2000s.
Although per capita availability of milk has increased from $128 \mathrm{~g} /$ day in $1980-81$ to 290 g/ day in 2011-12, it is little above the requirement of $286 \mathrm{~g} /$ day (Anonymous, 2012-17).

The contribution of farm women in dairy production activities was studied to their percent involvement in the decision-making process. Involvement in the decision making of an individual family member may not be of the same level for all activities of dairy production. In some cases, the farm women might decide on their own, while in others they might not be involved at all. The involvement of farm women in decision making was studied under the category of feeding, breeding, management, health care, and processing of milk. (Chayal and Dhaka, 2010).

Participation of women in different dairy farm activities: In India, majority of dairy farm women participated in the care of newborn calf, milking, cleaning of animal shed, cleaning of utensils, weaning and management of calf, preparation of cow dung cakes and construction of animal sheds but their participation was least in the maintenance of farm records. The involvement of farm women in the care of newborn calf and cleaning of utensils and a shed was 100 percent (Uma Sah et al., 2006; Chayal et al., 2009 and Lahoti et al., 2012). Women performed activities like milking (90 percent), cleaning of animal sheds (89.16 percent) and disposal of cow dung or preparation of cow dung cakes 86.66 percent (Rathod et al., 2011). Men contributed about 50 percent of the labour involved in grazing activity only. All other activities such as cleaning shed, milking, harvest, and transports of grass for livestock were performed exclusively by women (Johnson et $a l .$, 2013). The participation of farm women was least in the economic activities like 
taking loans, purchase and sale of animals and choosing animals for dairy. Because of traditional Indian culture, the decision regarding economic aspects has been taken by men. Moreover, farm women have less contact with progressive farmers, officials, and banks. This was also the reason for a low level of involvement in decision-making (Upadhyay and Desai, 2011). Milk and milk products play a vital role in the country's agricultural economy. It provides sustenance to millions of farmers, particularly the rural poor. Dairy development fits most appropriate in the country's programs of increasing rural employment and equitable distribution of income with justice.

The veterinary and animal husbandry offers a great potential for improvement of rural economy and overall development of the state through the adoption of improved breeding, feeding, management, healthcare, processing, and marketing system. Traditionally, women are responsible for the activities such as giving feed and water to the animals, cleaning and bathing of animals, maintenance and cleaning of cattle shed, fodder collection, collection of cow dung, and preparation of cow-dung cakes, and preparation of milk products. They also participate frequently in taking care of sick animals, care of pregnant animals, care of newborn calves, milking, and grazing of the animals.

A well-articulated policy support in terms of access to and control of productive and natural resources such as land, lease of rural water-bodies, livestock, micro-credit, veterinary services, and assured markets will strengthen women's influence and socioeconomic empowerment (Kumar et al., 2012). Keeping the above point the present study was undertaken to properly assess the participation of rural women in the decisionmaking process of dairy farming in Surguja district of Chhattisgarh.

\section{Materials and Methods}

The study was conducted during the year 2017 in the Surguja district of the Chhattisgarh state. The Chhattisgarh state consists of 27 districts, out of which the Surguja district was selected purposively. Out of a total of seven blocks in Surguja only One block namely Ambikapur was selected purposively for the present study from Ambikapur block, 4 villages were selected based on maximum availability of animal husbandry in the villages. In this way, the villages, Sakalo, Sargawan, Bhitthi Kalan, Mendra Kalan from Ambikapur block were selected for the study. A list of farm families who are engaged in Dairy farming was prepared.

From the list of each selected village, 30 farm families were selected randomly. In this way, a total of 120 farm families $(30 * 4=120)$, were selected as respondents for the collection of data. The data were collected by personal interviews with the help of a pretested structure Interview schedule. The statistical measures such as percentage, mean score, standard deviation, and correlation coefficient and path analysis were used with the help of SPSS software as well as OPSTAT website.

\section{Results and Discussion}

The findings of the study as well as relevant discussion have been summarized under the following Subhead

\section{Participation of rural women in decision making process of dairy farming}

The Data regarding the participation of rural women in the decision-making process in Dairy farming are presented in Table 1: that maximum no of the respondents $(100 \%)$ had medium participation (46.4 to $88.2 \%$ ) and 
none of the respondents belonged to low or high participation group in the decisionmaking process in Dairy farming. It can be concluded that all of the respondents belonged to a medium level of participation.

It was graphically shown from Figure 1 that the level of participation of rural women in the decision-making process of dairy farming in percentage terms.

Correlation analysis of independent variables with participation of rural women in decision making process of dairy farming

As seen from Table 2 Annual income(X7) is significantly associated with the extent of participation of rural women in the decisionmaking process in Dairy farming. The table also reveals that the Age (X1), Education (X2), Caste (X3), Family size (X4), Type of family (X5), Farm size (X6), Socialparticipation (X8), Dairy experience (X9), Source of information (X10) showed a nonsignificant association with extent of participation of rural women in Decisionmaking process in Dairy farming. Correlation Coefficient between the selected characteristics of the respondents with participation in Dairy farming was also worked out and the value of the Correlation coefficient was analyzed. It is clear from the data that out of all selected 10 variables only 1 variable Annual income was found positively and significantly correlated with Extent of participation of rural women in the Decision-making process in Dairy farming practices. Remaining a variable did not indicate any significant relationship with the Extent of participation of rural women in the decision-making process in Dairy farming. Correlation Coefficient between the selected characteristics of the respondents with participation in Dairy farming was also worked out and the value of correlation coefficient was analyzed. It is clear from the data that out of all selected 10 variables only 1 variable Annual income was found positively and significantly correlated with Extent of participation of rural women in the Decision-making process in Dairy farming practices. Remaining a variable did not indicate any significant relationship with the Extent of participation of rural women in the decision-making process in Dairy farming,

\section{Path analysis: participation of rural women in decision making process of dairy farming}

Path analysis is a technique that aims at determining the direct and indirect effects among the number of variables and thereby helps to a quantitative interpretation of the interrelationships within a known or an assumed casual system that exists in some specific population. The basic theorem of path analysis states that the zero-order correlation between any two variables is equals to the sum of the products of the paths and correlations between all the variables in the system. In this technique, the direct and indirect effects are measured by a quantity (standardized partial regression) called the path coefficient. A path coefficient is an absolute number without any physical unit, whatever the actual units of measurement for the variables. It indicates the extent to which the variance in a dependent variable is determined by the variance of the independent variable. The result extracted from path analysis shows that the independent variable affected (direct and indirect effect) on the Participation of rural women in the decision making process of dairy farming.

It has been found Table 3 that the variable Age (X1) has the highest total indirect effect on the Participation of rural women in the decision making process of dairy farming (Y1) Education (X2) and type of family (X5) 
has been second and third position respectively. Age (X1) had the highest direct effect remaining annual income (X7) and Social participation (X8) has been the Second and third passion direct effect respectively. Annual income (X7) had the highest total effect on the Participation of rural women in the decision-making process of dairy farming where Type of family (X5) and Social participation (X8) has been the second and third passion in total effect respectively.

The potential explanation for this assumption may be that respondents with greater holdings will be likely to seek to take specific scientific modifications. As a Participation of rural women in the decision-making process of dairy farming results, respondent with a larger annual income are likely to have a strong desire to know about and be more open to a new practice, thus improving the know-how, types of family and Social participation which directly and indirectly imitate their Participation of rural women in the decisionmaking process of dairy farming

Milking practice has a positive impact on the participation of rural women in the decisionmaking process of dairy farming, as it provides the basis for the dynamic potential of dairy farming, the opportunity to learn and adapt to changing circumstances. The logical explanation might be that dairy farmers with annual income may be more involved in and employ the latest innovation in their dairy farming. These findings are consistent with the observations provided (Porchezhiyan et al., 2016).

Table.1 Participation of rural women in decision making process of dairy farming $\mathrm{n}=120$

\begin{tabular}{|c|c|c|}
\hline Category & Frequency & Percentage \\
\hline Low (below 46.4\%) & 0 & 0 \\
\hline Medium (46.4 to $88.2 \%$ ) & 120 & 100 \\
\hline High (more than $88.2 \%$ ) & 0 & 0 \\
\hline Total & 120 & 100 \\
\hline $\mathrm{SD}=\mathbf{2 0 . 8 8}$ & & \\
\hline
\end{tabular}

Table.2 Correlation analysis between different variables $n=120$

\begin{tabular}{|l|c|}
\hline Independent variable & Correlation coefficient value (r) \\
\hline $\mathbf{X}_{\mathbf{1}}$ Age & .021 \\
\hline $\mathbf{X}_{\mathbf{2}}$ Education & .034 \\
\hline $\mathbf{X}_{\mathbf{3}}$ Caste & .116 \\
\hline $\mathbf{X}_{\mathbf{4}}$ Family size & .082 \\
\hline $\mathbf{X}_{\mathbf{5}}$ Type of family & -.140 \\
\hline $\mathbf{X}_{\mathbf{6}}$ Farm size & .103 \\
\hline $\mathbf{X}_{\mathbf{7}}$ Annual income & -.189 \\
\hline $\mathbf{X}_{\mathbf{8}}$ Social participation & .127 \\
\hline $\mathbf{X}_{\mathbf{9}}$ Dairy experience & .055 \\
\hline $\mathbf{X}_{\mathbf{1 0}}$ Source of information & .058 \\
\hline *Correlation is significant & at the level $\mathbf{0 . 0 5}$ level \\
\hline
\end{tabular}


Table.3 Path Analysis: Participation of rural women in decision making process of dairy farming (Y) Vs 10 Variable

\begin{tabular}{|l|c|c|c|}
\hline \multicolumn{1}{|c|}{ Variable } & Total indirect effect & Direct effect & Total effect \\
\hline $\mathbf{X}_{\mathbf{1}}$ Age & -0.157 (first) & 0.178 (first) & 0.021 \\
\hline $\mathbf{X}_{\mathbf{2}}$ Education & -0.125 (second) & 0.159 & 0.034 \\
\hline $\mathbf{X}_{\mathbf{3}}$ Caste & 0.015 & 0.101 & 0.116 \\
\hline $\mathbf{X}_{\mathbf{4}}$ Family size & 0.044 & 0.038 & 0.082 \\
\hline $\mathbf{X}_{\mathbf{5}}$ Type of family & -0.108 (third) & -0.032 & -0.140 \\
\hline & & & $($ second) \\
\hline $\mathbf{X}_{\mathbf{6}}$ Farm size & -0.033 & 0.136 & 0.103 \\
\hline $\mathbf{X}_{\mathbf{7}}$ Annual income & -0.012 & -0.177 (second) & -0.189 (first) \\
\hline $\mathbf{X}_{\mathbf{8}}$ Social participation & -0.035 & 0.162 (third) & 0.127 (third) \\
\hline $\mathbf{X}_{\mathbf{9}}$ Dairy experience & 0.039 & 0.016 & 0.055 \\
\hline $\mathbf{X}_{\mathbf{1 0}}$ Source of information & -0.012 & 0.070 & 0.058 \\
\hline
\end{tabular}

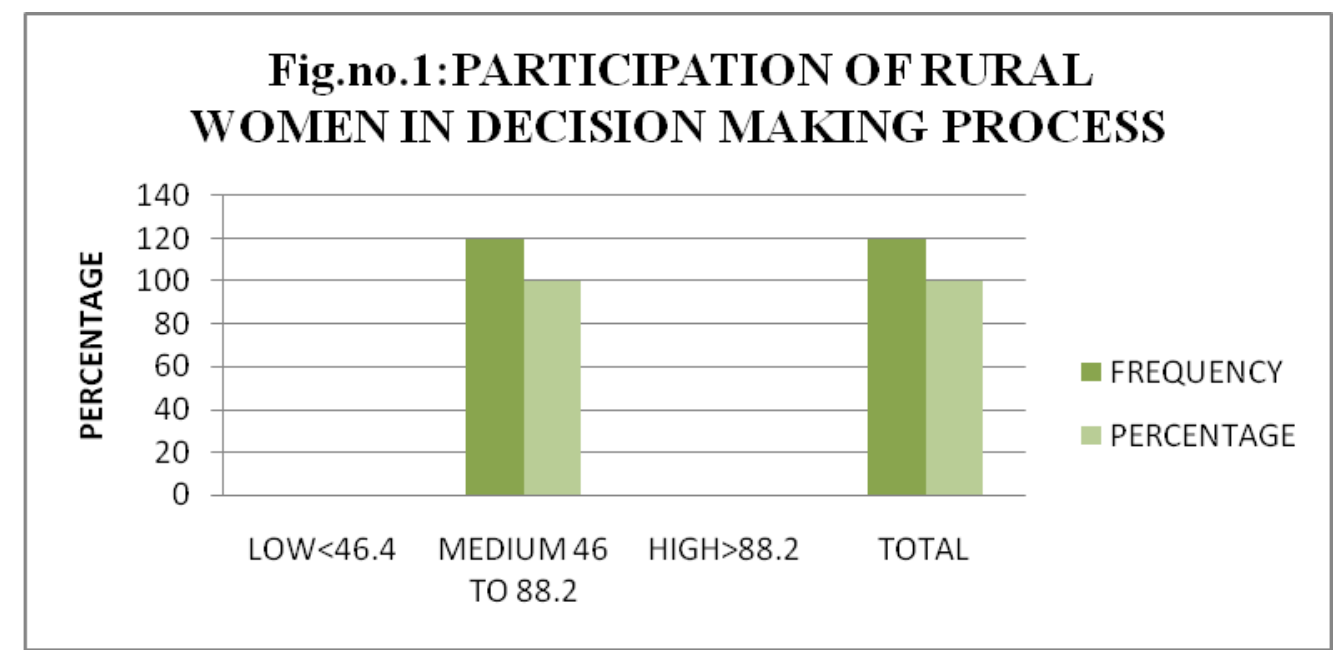

Figure.1 Participation of rural women in decision making process of dairy farming

The study was concluded that the maximum number $(100 \%)$ of respondents had a medium level of rural women participation in the decision making process of dairy farming.

Among of all selected 10 variables, only 1 variable Annual income was found positive and significantly correlated with Extent of participation of rural women in the Decisionmaking process in Dairy farming practices. The remaining variables did not indicate any significant relationship with the extent of participation of rural women in the decisionmaking process in Dairy farming. Path analysis shows that annual income (X15) had the highest total effect on the participation of rural women in the decision-making process of dairy farming where the family type (X5) and Social participation (X8) has been the second and third passion of total effect on Participation of rural women in the decisionmaking process of dairy farming respectively.

\section{Suggestions for future works}

Based on results and experience gained after the completion of the investigation the following points are suggested for further studies: 
1. The present study is an effort to analyze the contribution of livestock to the livelihood security of farmers in production units of Surguja district by considering only a set of variables. Similar studies using more systematic and sophisticated tools to precisely assess livestock contribution may be taken up covering more sample farmers and larger areas with many related variables.

2. The similar study on other enterprise need to be undertaken to investigate the knowledge level of respondents in different agro-climatic zone of Chhattisgarh.

3. A similar study on forest produce needs to be conducted to understand the participation of tribal women in tribal dominant regions of the state.

\section{References}

Anonymous, (2012-17). A Report of the Working Group on Animal Husbandry $\&$ Dairying $12^{\text {th }}$ Five Year Plan, New Delhi.

Chayal, K., and Dhaka, B.L. (2010). Analysis of role performance of women in farm activities. Indian Res. J. Ext. Edu., 10(2): 109-112.

Chayal, K., Daaka, B.L., and Suwalka, R.L. (2009). Analysis of role performed by farm women in dairy farming. Indian. J. Dairy. Sci., 62: 491-494

Johnson, J.N., Govindaradjane, S. and
Sundararajan, T. (2013). The role of rural women in watershed development projects. International J. Engineering Sci. and Innovative Technology., 2(1): 540-544.

Kumar, A. 2008. Farm women's knowledge and adoption of dairy practices in Junagadh District of Gujarat. M. Sc. (Agri.) Thesis (Unpublished), J.A.U., Junagadh.

Lahoti, S.R., Chole, S.R. and Rathi, N.S. (2012). Role of women in dairy farming. Indian J. Dairy Sci., 65(5): 442-446.

Porchezhiyan, S., Sudharshan, A. and Umamageswari, $\quad$ M. 2016. Entrepreneurial behavioral index of dairy farmers in the Northern districts of Tamil Nadu. Indian J. Eco. Develop., 4(1): 2320-9828.

Rathod, P.K., Nikam, T.R., Sariput, L., Vajreshwari, S. and Amit, H. (2011). Participation of rural women in dairy farming in Karnataka. Indian Res. J. Ext. Edu., 11(2): 31-35.

Uma sah., Shantanu, K. and Fulzele, R.M. (2006). Perceived needs of dairy farmers and farm women related to improved dairy farming in India- an overview. Agric. Rev., 23(1): 65 - 70.

Upadhyay, S. and Desai, C.P. (2011). Participation of farm women in animal husbandry in Anand District of Gujarat. J. Community Mobilization and Sustainable Development., 6(2): 117121.

\section{How to cite this article:}

Ankur Gupta, Anindita Saha, Ravi Kumar Gupta and Digvijay Singh Dhakre. 2020. Participation of Rural Women in Decision Making Process of Dairy Farming in Surguja District of Chhattisgarh, India. Int.J.Curr.Microbiol.App.Sci. 9(06): 2982-2988. doi: https://doi.org/10.20546/ijcmas.2020.906.358 